\title{
Educational games for brain health: revealing their unexplored potential through a neurocognitive approach
}

\author{
Patrick Fissler $^{1 *}$, Iris-Tatjana Kolassa ${ }^{1}$ and Claudia Schrader ${ }^{2}$ \\ ${ }^{1}$ Institute of Psychology and Education, Clinical and Biological Psychology, Ulm University, Ulm, Germany, ${ }^{2}$ Institute of \\ Psychology and Education, Serious Games, Ulm University, Ulm, Germany
}

OPEN ACCESS

Edited by:

Howard T. Everson,

City University of New York, USA

Reviewed by:

Alys Jordan,

University of Alaska Fairbanks, USA

Barbara Colombo,

Catholic University of the Sacred Heart, Italy

Bruce D. Homer,

The Graduate Center, CUNY, USA

*Correspondence:

Patrick Fissler,

Institute of Psychology and Education,

Clinical and Biological Psychology,

Ulm University, Albert-Einstein-Allee

47, 89081 Ulm, Germany

patrick.fissler@uni-ulm.de

Specialty section:

This article was submitted to Educational Psychology, a section of the journal

Frontiers in Psychology

Received: 04 March 2015

Accepted: 10 July 2015

Published: 24 July 2015

Citation:

Fissler P, Kolassa I-T and Schrader C (2015) Educational games for brain health: revealing their unexplored potential through a neurocognitive

approach.

Front. Psychol. 6:1056.

doi: 10.3389/fpsyg.2015.01056
Educational games link the motivational nature of games with learning of knowledge and skills. Here, we go beyond effects on these learning outcomes. We review two lines of evidence which indicate the currently unexplored potential of educational games to promote brain health: First, gaming with specific neurocognitive demands (e.g., executive control), and second, educational learning experiences (e.g., studying foreign languages) improve brain health markers. These markers include cognitive ability, brain function, and brain structure. As educational games allow the combination of specific neurocognitive demands with educational learning experiences, they seem to be optimally suited for promoting brain health. We propose a neurocognitive approach to reveal this unexplored potential of educational games in future research.

Keywords: educational games, serious games, brain health, gaming, education, cognitive ability, brain function, brain structure

\section{The Power of Educational Games}

Playing games is one of the most popular leisure activities. For example, 59\% of Americans play video games (Entertainment Software Association, 2014). In contrast to watching a video or reading a book, video games afford interactive exploration and challenge due to user control, competition, levels of difficulty, and reward (Malone, 1981; Lucas and Sherry, 2004). These design characteristics are essential for player's motivation in games (Sweetser and Wyeth, 2005).

Educational games aim to use this motivational quality of games for educationally relevant learning purposes (knowledge and skill acquisition). They are a branch of serious games which are defined as "games that do not have entertainment, enjoyment or fun as their primary purpose" (Michael and Chen, 2006, p. 21). Domains of learning include history, engineering, biology, math, and language (Young et al., 2012; Wouters et al., 2013). For example, Re-mission aims to improve cancer-related knowledge (Beale et al., 2007) and Twelve a Dozen ${ }^{1}$ teaches mathematical operations. The number of these games increased exponentially since the 1990s in industry and in research (Laamarti et al., 2014). A recent meta-analysis by Wouters et al. (2013) investigated the effectiveness of educational games in terms of learning. It included 77 studies with more than 5,500 participants and found that the games induced even more knowledge and skill acquisition than conventional instruction methods.

In this perspective article, however, we go beyond educational games' effects on learning of knowledge and skills (i.e., plasticity of representations, cf. Craik and Bialystok, 2006; Lövdén et al., 2010). We review research which suggests the currently unexplored potential of educational games

\footnotetext{
${ }^{1}$ http://www.bossastudios.com/games/twelve/
} 


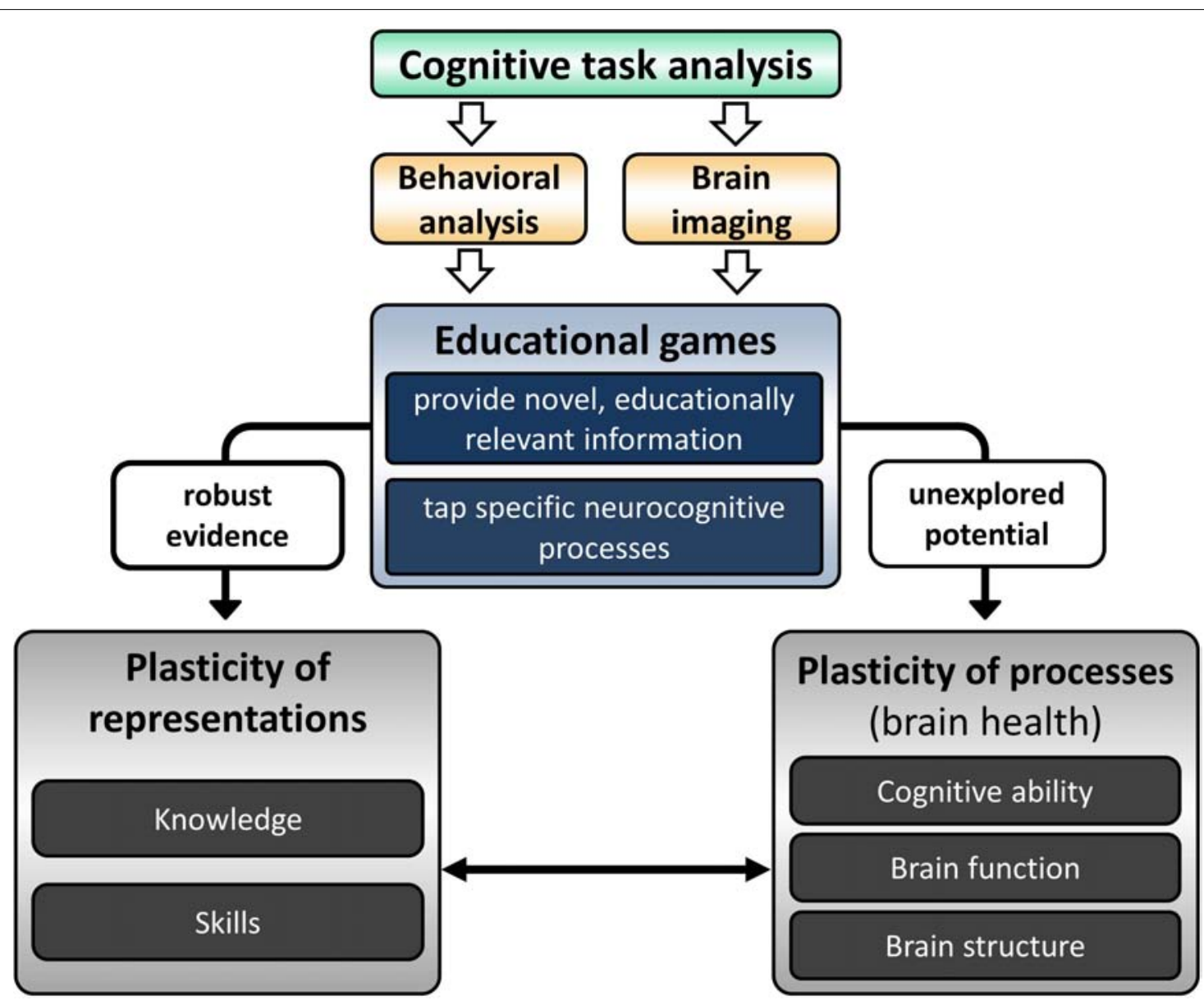

FIGURE 1 | A neurocognitive approach to reveal the unexplored potential of educational games for brain health. In a two-step approach, a cognitive task analysis of educational games is followed by their validation through objective methods. This second step consists of a behavioral analysis to determine the association between game performance and neuropsychological test performance and/or a brain imaging approach to determine the recruited neuronal networks for task completion. Based on this approach, appropriate educational games can be selected to enable randomized controlled clinical trials that assess the efficacy of educational games to improve brain health markers including cognitive ability, brain function, and brain structure. for brain health (i.e., plasticity of processes, cf. Craik and Bialystok, 2006; Lövdén et al., 2010) and propose a neurocognitive approach to reveal this potential.

First, we briefly review evidence for the beneficial effect of games with specific neurocognitive demands on brain health. Second, we depict the positive impact of educationally relevant learning experiences on brain health. Educational games enable both specific neurocognitive demands and educational learning experience. However, to our knowledge, there are currently no studies exploring their potential for brain health. Hence, in the last section, we propose a two-step neurocognitive approach to identify appropriate educational games that should be rigorously tested in randomized controlled clinical trials (see Figure 1).

\section{Gaming with Specific Neurocognitive Demands Promotes Brain Health}

The supply-demand mismatch model of cognitive plasticity assumes that neurocognitive demands which are greater than the brain's functional supply induce beneficial neuroplastic changes (Lövdén et al., 2010). It is assumed that this supply-demand mismatch needs to be prolonged (at least more than several hours for small effect sizes) to overcome the inertia and sluggishness of plasticity (Lövdén et al., 2010). Games can pose prolonged neurocognitive demands on working memory, perceptual speed, and episodic memory (Baniqued et al., 2013). Thus, games might induce respective neurocognitive benefits. For example, games that heavily tap executive control processes such as working memory are thought to induce positive plastic changes in these cognitive processes and their underlying prefrontal network. Such changes may range from more efficient brain function (Bavelier et al., 2012; Anguera et al., 2013) to benefits in brain structure such as increases in gray matter volume (Kühn et al., 2013), cortical thickness (Kühn et al., 2014), and neurotransmitter receptors (McNab et al., 2009).

Current advances in gaming research support the supplydemand mismatch model (see Powers et al., 2013; Bisoglio et al., 2014 for a meta-analysis and a review). Cognitively demanding digital games as well as non-digital board and card 
games improved cognitive abilities (Cheng et al., 2013; Fissler et al., 2013; Powers et al., 2013). These gaming-induced benefits comprised lower-order abilities such as visual perception (Green and Bavelier, 2012) and higher-order abilities such as selective visual attention (Green and Bavelier, 2003), switching ability (Basak et al., 2008; Green et al., 2012; Strobach et al., 2012), sustained attention (Anguera et al., 2013), short-term and working memory (Basak et al., 2008; Anguera et al., 2013; Cheng et al., 2013), executive control (Fissler et al., 2013), reasoning, and spatial abilities (Feng et al., 2007; Shute et al., 2015).

For example, a study by Shute et al. (2015) showed that a commercial off-the-shelf game called Portal 2 with processspecific demands on spatial reasoning improved cognitive abilities even more than an intentionally-designed cognitive training program (i.e., repeated practice of standardized cognitive task paradigms for specific cognitive abilities with adapting difficulty levels, Gates and Valenzuela, 2010). In contrast to participants following the cognitive training program, Portal 2 players improved more in performance on non-trained problem solving and spatial ability tests. Furthermore, playing the video game was more enjoyable than the cognitive training program (Shute et al., 2015).

Recent studies provide first insights into the neuronal underpinning of game-induced cognitive benefits. They range from plastic changes in brain structure to brain function. Kühn et al. (2013) found that playing Super Mario 64 increased gray matter of the right hippocampal formation and dorsolateral prefrontal cortex as well as of the cerebellum bilaterally. These brain areas are known to play an essential role in spatial memory, executive function, and fine-tuned motor skills. Using electrophysiological methods, Anguera et al. (2013) demonstrated functional brain benefits in the prefrontal cognitive control system through a dual-task driving game called NeuroRacer. Importantly, non-trained neuropsychological test performance improved through training and these gains were positively associated with the neurofunctional changes.

These experimental findings are backed by observational studies on the association of gaming with brain health markers. Frequent players of board games, in contrast to rare players, showed a reduced cognitive decline and incidence of dementia (Verghese et al., 2003; Dartigues et al., 2013). Bavelier et al. (2012) investigated associations of brain function with gaming experience. Frequent gamers, in contrast to non-gamers, showed reduced neuronal recruitment of the fronto-parietal network in attentionally challenging tasks which indicates more efficient attentional processing. Finally, associations of gaming with brain structure were recently revealed. The duration of video gaming (hours per week) was positively associated with left prefrontal cortical thickness (Kühn et al., 2014). The number of years spent video gaming was positively related to entorhinal cortex, hippocampal, and occipital gray matter volume (Kühn and Gallinat, 2014).

In sum, these recent advances in gaming research emphasize the potential of cognitively challenging games to improve different markers of brain health ranging from cognitive ability, brain function, and brain structure to incidence of dementia. In the following, we will outline the impact of educationally relevant learning of knowledge and skills on brain health markers.

\section{Educational Learning Experiences Promote Brain Health}

Extensive learning experiences are thought to require prolonged activation of basic neurocognitive abilities such as executive control processes and long-term memory (Park et al., 2014). These prolonged neurocognitive demands may induce positive plastic changes in accordance with the supply-demand mismatch model (Lövdén et al., 2010). Successful learning experiences may enhance brain health by additional mechanisms as evidenced in animal models. Learning novel information increased survival of newborn cells in the hippocampus, an area that plays an essential role for episodic memory (see Shors, 2014, for a review). In addition, intrinsic plasticity-a metaplasticity mechanism which changes the threshold for intrinsic neuronal excitability-is increased in the hippocampus through successful learning experiences (see Sehgal et al., 2013, for a review). Furthermore, an enriched environment, which provides a range of learning opportunities, reduced pathological processes that are associated with Alzheimer's disease (Lazarov et al., 2005; Costa et al., 2007) and reduced the detrimental effect of Alzheimer's disease-related A $\beta$ oligomers on long-term potentiation (Li et al., 2013).

A positive effect of educationally relevant learning experiences on markers of brain health has also been found in experimental studies with humans. Diverse interventions targeting at knowledge and skill acquisition improved cognitive abilities. Extensive learning experiences within a senior computer course improved working memory and episodic memory (Klusmann et al., 2010). A digital-photography and quilting course improved episodic memory (Park et al., 2014). A tablet course improved speed and episodic memory (Chan et al., 2014) and extensive training of a foreign language enhanced associative memory (Mårtensson and Lövdén, 2011). For example, Park et al. (2014) investigated the cognitive benefits of acquiring digitalphotography skills by the use of a single-lens reflex camera and photo-editing software $15 \mathrm{~h}$ a week for 3 months. Compared to a group which completed activities that relied on activation of prior knowledge (e.g., listening to music, watching DVDs, or completing word-meaning puzzles), their episodic memory performance improved more (Park et al., 2014).

In addition, extensive educational learning interventions induced plasticity in brain function (i.e., increased activity in the anterior cingulum, Carlson et al., 2009) and brain structure (Draganski et al., 2006; Woollett and Maguire, 2011). The hippocampus increased in volume after extensive learning for medical exams (Draganski et al., 2006) and after successful training for a London taxi driver license (Woollett and Maguire, 2011).

This interventional evidence is backed by robust observational evidence regarding the relationship of education with brain health markers. Strong positive associations between years spent in education and risk for cognitive decline (Valenzuela and Sachdev, 2006) as well as dementia (Caamaño-Isorna et al., 2006) have been demonstrated. Low education represents the single most 
preventable risk factor for Alzheimer's dementia. Worldwide, 19\% of affected individuals are potentially attributable to low education (Barnes and Yaffe, 2011). In addition, acquisition of skills such as speaking a second language and playing a musical instrument predicted a reduced future risk of cognitive decline (Bak et al., 2014) and dementia (see e.g., Balbag et al., 2014, for a populationbased twin study). Furthermore, more years spent in education was associated with greater brain weight (Brayne et al., 2010) and, in one pilot-study, also with lower markers of Alzheimer's disease pathology (Yasuno et al., 2014).

In the last two sections, we reviewed evidence for beneficial effects on brain health a) through gaming-induced neurocognitive demands and b) through educationally relevant learning of knowledge and skills. As educational games allow the combination of both, they seem to be optimally suited to promote brain health. However, to our knowledge, no study investigated the impact of educational gaming on brain health markers, yet. Hence, we propose a two-step neurocognitive approach in the following section that aims to reveal their unexplored potential.

\section{A Neurocognitive Approach to Reveal the Potential of Educational Games for Brain Health}

We have outlined above that games which induce learning of novel information and pose specific neurocognitive demands seem to be optimally-suited for brain health purposes. Clearly, not all educational games pose specific neurocognitive demands and appropriate games need to be identified from the large and growing market (cf. Wartella, 2015). We propose a two-step approach to elucidate the neurocognitive demands of educational games (see Figure 1).

In the first step, a cognitive task analysis should be conducted for a wide range of educational games in order to determine the most appropriate cognitively challenging games for the more cost-intensive second step. Cognitive task analysis is a set of methods aiming to determine the cognitive demands to perform a task proficiently (Militello and Hutton, 1998). We briefly depict one approach of a cognitive task analysis suited for educational games (cf. Baniqued et al., 2013) and exemplify this method with DragonBox2, an educational game which aims to teach algebra in a fun way ${ }^{2}$.

First, a game diagram is created to determine the cognitively demanding tasks of the respective educational game. Here, an expert for the game (1) breaks the game down into its major tasks (usually between one and five tasks) and (2) determines which tasks pose substantial demands on cognitive abilities such as attention, speed or memory (cf. task diagram method; Militello and Hutton, 1998). In DragonBox2, there is one major task (i.e., isolating a dragon captured in a box on one side of the screen, or in other words, solving an algebraic equation for the $x$ ) and this task poses substantial cognitive demands.

Subsequently, neuropsychologists should rate the major tasks of appropriate educational games on their specific neurocognitive

$\overline{2 \text { http://www.dragonboxapp.com/ }}$ demands. The rating should be based on a validated taxonomy of neurocognitive abilities. For example, executive functions can be subdivided in three components including updating, inhibition, and shifting (Miyake et al., 2000; Miyake and Friedman, 2012). Memory can be subdivided in the two components declarative memory and procedural memory (Squire, 1992; Robertson, 2009). DragonBox 2 poses high demands on executive function (frontal brain systems) and memory (mediotemporal and basal ganglia systems). For example, monitoring multiple items which are added and deleted from working memory through the mental application of algebra rules poses demands on updating; flexibly switching between multiple algebra rules which are cued by a given stimulus set requires shifting; selecting the application of non-dominant rules instead of more prepotent rules poses demands on inhibition; knowledge acquisition for the game's 24 algebra rules taps declarative memory; skill acquisition regarding arithmetics, factorization, or the creation of parameters poses demands on procedural memory.

In the more cost-intensive second step, two objective methods-a behavioral and/or a brain imaging approach-can be used to substantiate the assumed neurocognitive demands revealed by the cognitive task analysis. In the behavioral approach, associations between game performance and performance in neuropsychological tests are assessed (cf Jaeggi et al., 2010; Baniqued et al., 2013; Rode et al., 2014). The pattern of the game-test associations enables the validation of the games' neurocognitive demands.

The brain imaging approach aims to reveal the neuronal networks recruited by the games. Different brain imaging methods such as electroencephalography (Anguera et al., 2013), near-infrared spectroscopy (Ekkekakis, 2009), or functional magnetic resonance imaging (Dahlin et al., 2008; Voss et al., 2012) can be used. Finally, after successful identification of appropriate educational games through behavioral analysis and/or brain imaging, long-term randomized controlled clinical trials should examine their effects on brain health markers (see Moher et al., 2010, for methodological issues).

\section{Conclusion}

In this perspective article, we reviewed two lines of research that indicate an unexplored potential of educational games to improve brain health. First, games with specific neurocognitive demands and second, educationally relevant learning experiences positively impact brain health markers including cognitive abilities, brain function, and brain structure. Future research should use a neurocognitive approach to identify cognitively challenging educational games. These should be rigorously examined in randomized controlled long-term clinical trials regarding their effects on brain health.

\section{Acknowledgments}

We thank Laura Loy for her valuable and fruitful comments on the manuscript and Heather Foran for English proofreading. 


\section{References}

Anguera, J. A., Boccanfuso, J., Rintoul, J. L., Al-Hashimi, O., Faraji, F., Janowich, J., et al. (2013). Video game training enhances cognitive control in older adults. Nature 501, 97-101. doi: 10.1038/nature12486

Bak, T. H., Nissan, J. J., Allerhand, M. M., and Deary, I. J. (2014). Does bilingualism influence cognitive aging? Ann. Neurol. 75, 959-963. doi: 10.1002/ana.24158

Balbag, M. A., Pedersen, N. L., and Gatz, M. (2014). Playing a musical instrument as a protective factor against dementia and cognitive impairment: a populationbased twin study. Int. J. Alzheimers Dis. 2014, 6. doi: 10.1155/2014/836748

Baniqued, P. L., Lee, H., Voss, M. W., Basak, C., Cosman, J. D., Desouza, S., et al. (2013). Selling points: what cognitive abilities are tapped by casual video games? Acta Psychol. 142, 74-86. doi: 10.1016/j.actpsy.2012.11.009

Barnes, D. E., and Yaffe, K. (2011). The projected effect of risk factor reduction on Alzheimer's disease prevalence. Lancet Neurol. 10, 819-828. doi: 10.1016/S14744422(11)70072-2

Basak, C., Boot, W. R., Voss, M. W., and Kramer, A. F. (2008). Can training in a realtime strategy video game attenuate cognitive decline in older adults? Psychol. Aging 23, 765-777. doi: 10.1037/a0013494

Bavelier, D., Achtman, R. L., Mani, M., and Föcker, J. (2012). Neural bases of selective attention in action video game players. Vision Res. 61, 132-143. doi: 10.1016/j.visres.2011.08.007

Beale, I. L., Kato, P. M., Marin-Bowling, V. M., Guthrie, N., and Cole, S. W. (2007). Improvement in cancer-related knowledge following use of a psychoeducational video game for adolescents and young adults with cancer. J. Adolesc. Health 41, 263-270. doi: 10.1016/j.jadohealth.2007.04.006

Bisoglio, J., Michaels, T. I., Mervis, J. E., and Ashinoff, B. K. (2014). Cognitive enhancement through action video game training: great expectations require greater evidence. Front. Psychol. 5:136. doi: 10.3389/fpsyg.2014. 00136

Brayne, C., Ince, P. G., Keage, H. a. D., Mckeith, I. G., Matthews, F. E., Polvikoski, T., et al. (2010). Education, the brain and dementia: neuroprotection or compensation? Brain 133, 2210-2216. doi: 10.1093/brain/awq185

Caamaño-Isorna, F., Corral, M., Montes-Martínez, A., and Takkouche, B. (2006). Education and dementia: a meta-analytic study. Neuroepidemiology 26, 226-232. doi: 10.1159/000093378

Carlson, M., Erickson, K., Kramer, A., Voss, M., Bolea, N., Mielke, M., et al. (2009). Evidence for neurocognitive plasticity in at-risk older adults: the experience corps program. J. Gerontol. Series A Biol. Sci. Med. Sci. 64, 1275-1282. doi: 10.1093/gerona/glp117

Chan, M. Y., Haber, S., Drew, L. M., and Park, D. C. (2014). Training older adults to use tablet computers: does it enhance cognitive function? Gerontologist doi: 10.1093/geront/gnu057 [Epub ahead of print].

Cheng, S.-T., Chow, P. K., Song, Y.-Q., Yu, E., Chan, A., Lee, T., et al. (2013). Mental and physical activities delay cognitive decline in older persons with dementia. Am. J. Geriatr. Psychiatry 10, 1-13. doi: 10.1016/j.jagp.2013.01.060

Costa, D. A., Cracchiolo, J. R., Bachstetter, A. D., Hughes, T. F., Bales, K. R., Paul, S. M., et al. (2007). Enrichment improves cognition in AD mice by amyloid-related and unrelated mechanisms. Neurobiol. Aging 28, 831-844. doi: 10.1016/j.neurobiolaging.2006.04.009

Craik, F., and Bialystok, E. (2006). Cognition through the lifespan: mechanisms of change. Trends Cogn. Sci. 10, 131-138. doi: 10.1016/j.tics.2006.01.007

Dahlin, E., Neely, A. S., Larsson, A., Backman, L., and Nyberg, L. (2008). Transfer of learning after updating training mediated by the striatum. Science 320, 1510-1512. doi: 10.1126/science.1155466

Dartigues, J. F., Foubert-Samier, A., Le Goff, M., Viltard, M., Amieva, H., Orgogozo, J. M., et al. (2013). Playing board games, cognitive decline and dementia: a French population-based cohort study. BMJ Open 3, e002998. doi: 10.1136/bmjopen-2013-002998

Draganski, B., Gaser, C., Kempermann, G., Kuhn, H. G., Winkler, J., Buchel, C., et al. (2006). Temporal and spatial dynamics of brain structure changes during extensive learning. J. Neurosci. 26, 6314-6317. doi: 10.1523/JNEUROSCI.462805.2006

Ekkekakis, P. (2009). Illuminating the black box: investigating prefrontal cortical hemodynamics during exercise with near-infrared spectroscopy. J. Sport Exerc. Psychol. 31, 505-553.

Entertainment Software Association. (2014). Essential Facts About the Computer and Video Game Industry. Available at: http://www.theesa.com/wp-content/ uploads/2014/10/ESA_EF_2014.pdf
Feng, J., Spence, I., and Pratt, J. (2007). Playing an action video game reduces gender differences in spatial cognition. Psychol. Sci. 18, 850-855. doi: 10.1111/j.14679280.2007.01990.x

Fissler, P., Küster, O., Schlee, W., and Kolassa, I. T. (2013). "Novelty interventions to enhance broad cognitive abilities and prevent dementia: synergistic approaches for the facilitation of positive plastic change," in Progress in Brain Research, eds M. M. Merzenich, M. Nahum, and T. M. Van Vleet (Oxford: Elsevier), 403-434.

Gates, N. J., and Valenzuela, M. (2010). Cognitive exercise and its role in cognitive function in older adults. Curr. Psychiatry Rep. 12, 20-27. doi: 10.1007/s11920009-0085-y

Green, C., and Bavelier, D. (2012). Learning, attentional control, and action video games. Curr. Biol. 22, R197-R206. doi: 10.1016/j.cub.2012.02.012

Green, C. S., and Bavelier, D. (2003). Action video game modifies visual selective attention. Nature 423, 534-537. doi: 10.1038/nature01647

Green, C. S., Sugarman, M. A., Medford, K., Klobusicky, E., and Bavelier, D. (2012). The effect of action video game experience on task-switching. Comput. Human Behav. 28, 984-994. doi: 10.1016/j.chb.2011.12.020

Jaeggi, S. M., Studer-Luethi, B., Buschkuehl, M., Su, Y. F., Jonides, J., and Perrig, W. J. (2010). The relationship between n-back performance and matrix reasoning-implications for training and transfer. Intelligence 38, 625-635. doi: 10.1016/j.intell.2010.09.001

Klusmann, V., Evers, A., Schwarzer, R., Schlattmann, P., Reischies, F., Heuser, I., et al. (2010). Complex mental and physical activity in older women and cognitive performance: a 6-month randomized controlled trial. J. Gerontol. A Biol. Sci. Med. Sci. 65, 680-688. doi: 10.1093/gerona/glq053

Kühn, S., and Gallinat, J. (2014). Amount of lifetime video gaming is positively associated with entorhinal, hippocampal and occipital volume. Mol. Psychiatry 19, 842-847. doi: 10.1038/mp.2013.100

Kühn, S., Gleich, T., Lorenz, R. C., Lindenberger, U., and Gallinat, J. (2013). Playing Super Mario induces structural brain plasticity: gray matter changes resulting from training with a commercial video game. Mol. Psychiatry 19, 265-271. doi: 10.1038/mp.2013.120

Kühn, S., Lorenz, R., Banaschewski, T., Barker, G. J., Büchel, C., Conrod, P. J., et al. (2014). Positive association of video game playing with left frontal cortical thickness in adolescents. PLoS ONE 9:e91506. doi: 10.1371/journal.pone.0091506

Laamarti, F., Eid, M., and El Saddik, A. (2014). An overview of serious games. Int. J. Comput. Games Technol. 2014, 15. doi: 10.1155/2014/358152

Lazarov, O., Robinson, J., Tang, Y. P., Hairston, I. S., Korade-Mirnics, Z., Lee, V. M. Y., et al. (2005). Environmental enrichment reduces $A \beta$ levels and amyloid deposition in transgenic mice. Cell 120, 701-713. doi: 10.1016/j.cell.2005.01.015

Li, S., Jin, M., Zhang, D., Yang, T., Koeglsperger, T., Fu, H., et al. (2013). Environmental novelty activates $\beta 2$-adrenergic signaling to prevent the impairment of hippocampal LTP by A $\beta$ oligomers. Neuron 77, 929-941. doi: 10.1016/j.neuron.2012.12.040

Lövdén, M., Bäckman, L., Lindenberger, U., Schaefer, S., and Schmiedek, F. (2010). A theoretical framework for the study of adult cognitive plasticity. Psychol. Bull. 136, 659-676. doi: 10.1037/a0020080

Lucas, K., and Sherry, J. L. (2004). Sex differences in video game play: a communication-based explanation. Commun. Res. 31, 499-523. doi: $10.1177 / 0093650204267930$

Malone, T. W. (1981). Toward a theory of intrinsically motivating instruction. Cogn. Sci. 5, 333-369. doi: 10.1207/s15516709cog0504_2

Mårtensson, J., and Lövdén, M. (2011). Do intensive studies of a foreign language improve associative memory performance? Front. Psychol. 2:12. doi: 10.3389/fpsyg.2011.00012

McNab, F., Varrone, A., Farde, L., Jucaite, A., Bystritsky, P., Forssberg, H., et al. (2009). Changes in cortical dopamine D1 receptor binding associated with cognitive training. Science 323, 800-802. doi: 10.1126/science.1166102

Michael, D. R., and Chen, S. L. (2006). Serious Games: Games that Educate, Train, and Inform. Boston, MA: Thomson Course Technology.

Militello, L. G., and Hutton, R. J. (1998). Applied Cognitive Task Analysis (ACTA): a practitioner's toolkit for understanding cognitive task demands. Ergonomics 41, 1618-1641. doi: 10.1080/001401398186108

Miyake, A., and Friedman, N. P. (2012). The nature and organization of individual differences in executive functions: four general conclusions. Curr. Dir. Psychol. Sci. 21, 8-14. doi: 10.1177/0963721411429458

Miyake, A., Friedman, N. P., Emerson, M. J., Witzki, A. H., Howerter, A., and Wager, T. D. (2000). The unity and diversity of executive functions 
and their contributions to complex. Cogn. Psychol. 41, 49-100. doi: 10.1006/cogp.1999.0734

Moher, D., Hopewell, S., Schulz, K. F., Montori, V., Gøtzsche, P. C., Devereaux, P. J., et al. (2010). CONSORT 2010 Explanation and Elaboration: updated guidelines for reporting parallel group randomised trials. BMJ 340, c869. doi: 10.1136/bmj.c869

Park, D. C., Lodi-Smith, J., Drew, L., Haber, S., Hebrank, A., Bischof, G. N., et al. (2014). The impact of sustained engagement on cognitive function in older adults: the synapse project. Psychol. Sci. 25, 103-112. doi: 10.1177/0956797613499592

Powers, K., Brooks, P., Aldrich, N., Palladino, M., and Alfieri, L. (2013). Effects of video-game play on information processing: a meta-analytic investigation. Psychon. Bull. Rev. 20, 1055-1079. doi: 10.3758/s13423-0130418-z

Robertson, E. M. (2009). From creation to consolidation: a novel framework for memory processing. PLoS Biol. 7:e1000019. doi: 10.1371/journal.pbio.1000019

Rode, C., Robson, R., Purviance, A., Geary, D. C., and Mayr, U. (2014). Is working memory training effective? A study in a school setting. PLoS ONE 9:e104796. doi: 10.1371/journal.pone.0104796

Sehgal, M., Song, C., Ehlers, V. L., and Moyer, J. R. Jr. (2013). Learning to learn-Intrinsic plasticity as a metaplasticity mechanism for memory formation. Neurobiol. Learn. Mem. 105, 186-199. doi: 10.1016/j.nlm.2013. 07.008

Shors, T. J. (2014). The adult brain makes new neurons, and effortful learning keeps them alive. Curr. Dir. Psychol. Sci. 23, 311-318. doi: 10.1177/0963721414540167

Shute, V. J., Ventura, M., and Ke, F. (2015). The power of play: the effects of Portal 2 and Lumosity on cognitive and noncognitive skills. Comput. Educ. 80, 58-67. doi: 10.1016/j.compedu.2014.08.013

Squire, L. R. (1992). Memory and the hippocampus: a synthesis from findings with rats, monkeys, and humans. Psychol. Rev. 99, 195-231. doi: 10.1037/0033295X.99.2.195

Strobach, T., Frensch, P. A., and Schubert, T. (2012). Video game practice optimizes executive control skills in dual-task and task switching situations. Acta Psychol. 140, 13-24. doi: 10.1016/j.actpsy.2012.02.001

Sweetser, P., and Wyeth, P. (2005). GameFlow: a model for evaluating player enjoyment in games. Comput. Entertain. 3, 3. doi: 10.1145/1077246.1077253
Valenzuela, M. J., and Sachdev, P. (2006). Brain reserve and cognitive decline: a non-parametric systematic review. Psychol. Med. 36, 1065-1073. doi: 10.1017/S0033291706007744

Verghese, J., Lipton, R., Katz, M., Hall, C., Derby, C., Kuslansky, G., et al. (2003). Leisure activities and the risk of dementia in the elderly. N. Engl. J. Med. 348, 2508-2516. doi: 10.1056/NEJMoa022252

Voss, M. W., Prakash, R. S., Erickson, K. I., Boot, W. R., Basak, C., Neider, M. B., et al. (2012). Effects of training strategies implemented in a complex videogame on functional connectivity of attentional networks. Neuroimage 59, 138-148. doi: 10.1016/j.neuroimage.2011.03.052

Wartella, E. (2015). Educational apps: what we do and do not know. Psychol. Sci. Public Interest 16, 1-2. doi: 10.1177/1529100615578662

Woollett, K., and Maguire, E. A. (2011). Acquiring the knowledge of London's layout drives structural brain changes. Curr. Biol. 21, 2109-2114. doi: 10.1016/j.cub.2011.11.018

Wouters, P., Van Nimwegen, C., Van Oostendorp, H., and Van Der Spek, E. D. (2013). A meta-analysis of the cognitive and motivational effects of serious games. J. Educ. Psychol. 105, 249-265. doi: 10.1037/a0031311

Yasuno, F., Kazui, H., Morita, N., Kajimoto, K., Ihara, M., Taguchi, A., et al. (2014). Low amyloid- $\beta$ deposition correlates with high education in cognitively normal older adults: a pilot study. Int. J. Geriatr. Psychiatry. doi: 10.1002/gps.4235 [Epub ahead of print].

Young, M. F., Slota, S., Cutter, A. B., Jalette, G., Mullin, G., Lai, B., et al. (2012). Our princess is in another castle: a review of trends in serious gaming for education. Rev. Edu. Res. 82, 61-89. doi: 10.3102/0034654312436980

Conflict of Interest Statement: The authors declare that the research was conducted in the absence of any commercial or financial relationships that could be construed as a potential conflict of interest.

Copyright (c) 2015 Fissler, Kolassa and Schrader. This is an open-access article distributed under the terms of the Creative Commons Attribution License (CC BY). The use, distribution or reproduction in other forums is permitted, provided the original author(s) or licensor are credited and that the original publication in this journal is cited, in accordance with accepted academic practice. No use, distribution or reproduction is permitted which does not comply with these terms. 